\title{
Feasibility of Anaerobic Digestion of Flotation Skim and Its Potential as Renewable Energy Source
}

\author{
Salam J. Bash Al-Maliky \\ Environmental Engineering/ AlMustansiriya University- Iraq \\ Research Scholar and Leader in Residence/ Ohio University-USA
}

\begin{abstract}
The high portions of organic and Greasy constituents of the skim of Induced Air Flotation (IAF) unit that is typically land disposed or rendered have made it environmentally problematic for the receiving bodies due to its poor natural solubility and degradability. One solution for that was the use of anaerobic digestion. Five laboratory scale batch reactors (each of $10 \mathrm{~L}$ working volume) were used herein to test the effect of different IAF skim to working volume ratios; namely $0.5,1.5,2.5,4.0,5.0: 10$ (R1-R5), while the rest of working volume was filled with livestock manure (as inoculums). These reactors were operated at two different temperatures (25C and $45 \mathrm{C}$ ), to determine the temperature effects on digestion performance. Chemical Oxygen Demand (COD) removal efficiencies of $72.6 \%, 68.6 \%, 60.1 \%, 52.1 \%$, and $43.25 \%$ were achieved for R1-R5 respectively, at temperature of $25 \mathrm{C}$. These removal efficiencies were significantly improved at temperature of $45 \mathrm{C}$, where efficiencies of $91.2 \%, 81.5 \%, 72.1 \%, 60.7 \%$ and about $50 \%$ were achieved for these reactors. In addition, very promising biogas production rates of 4.5- $5.8 \mathrm{l}$ /day were determined at operation temperatures of $45 \mathrm{C}$ (compared with 3-4 1/day at 25C) for the majority reactor life times. This achievement may compensate the treatment costs in addition to the supply of cheap renewable energy.
\end{abstract}

Author would like to acknowledge the logistic and technical support of the Institute of International Education IIE, Scholars Rescue Fund SRF and Russ College of Engineering/ Ohio University.

Keywords: Anaerobic digestion, Biogas, Digestion temperature, Induced Air Flotation, Substrate composition

Many recent researches and studies had demonstrated the great feasibility of applying the IAF approach for the removal of Oil and Grease (OG) from the effluents of municipal and industrial activities (Al-Maliky, 2010; Arnold and Stewart, 2008; Pan Li and Hideki Tsuge, 2006). IAF may simply be explained as a treatment process often used to remove this insoluble particulate matter from the wastewater, essentially to reduce the OG constituent, Biological Oxygen Demand (BOD), COD and Suspended Solids SS loads of the wastewater to avoid surcharges when discharging to surface water or municipal wastewater treatment plants. The process is achieved by injecting air bubbles into the water or wastewater in a flotation tank or basin. The small bubbles adhere to the suspended matter causing the suspended matter to float to the surface of the water where it may then be removed by a skimming device. The feed water to the IAF float tank is often dosed with a coagulant to flocculate the suspended matter (Hayatdavoudi, 2006).

Many studies had suggested various design and operation parameters for the IAF unit to achieve high performances in oil/water separation, reduction of BOD, TSS and COD (Al-Maliky, 2010; Van Ham, Behie and Svrcek, 2009), and in turn the production of skim sludge at the upper layer of a typical IAF unit that is characterized by high concentrations of OG, COD and TSS. Although that skim is typically rendered or land applied, but its poor natural degradability and high energy potential contents make it a potential candidate for anaerobic digestion. This approach needs careful handling to overcome the tendency of high OG concentrations to form a scum layer on the digester's liquid surface due to the poor solubility of OG at typical digester temperatures and the tendency to form a separate phase above the aqueous digester contents (Halalsheh et al., 2005). Suggestions to handle the later obstacle were either to reduce the IAF skim amounts to be digested or the use of some inoculums such as the agricultural wastes that improve microbial nutrition and provide $\mathrm{pH}$ buffering capacity (Bouallagui et al., 2009) .

Anaerobic treatment consists of the decomposition of organic material in the absence of free oxygen and this process produces biogas enriched in methane, carbon dioxide, ammonia and traces of other gases and Volatile Fatty Acids (VFA) within the reactor. The anaerobic treatment process has been employed in several developed countries with the aim of bio-stabilizing fermentable organic waste produced by rural and urban activities (Fernández, Pérez and Romero, 2010).

The main coal of this paper was to study the feasibility of an anaerobic digestion process as a final treatment of the skim of IAF unit that handles dairy industry`s waste water, and the potential of such process as renewable energy source, under different set ups of digest mixtures (IAF skim and livestock manure) and operation temperatures. Livestock manure was collected from Green Grass Farms, Athens, Ohio, USA.

\section{Characteristics of IAF skim}

The characteristic of having high COD concentration $(425 \mathrm{~g} / \mathrm{L})$ as shown in Table 1 gave the IAF skim a high potential of biogas production and encouraged increasing the ratio of IAF skim to manure in the reactor feed to 
supply a promising source of economic renewable energy, subject to the constraints due to microbial nutrition and $\mathrm{pH}$ buffering.

\section{Experimental Setup}

Five batch reactors (10 L working volume) were adopted for the test of anaerobic digestion parameters, as illustrated in Fig.1. Each reactor has an independent rotary blade mixer LIGHTNIN SPX so as to maintain uniform moisture content and to homogenize the soluble substrate and bacterial distribution. Also, an internal DUREX coil heater was inserted in each reactor, with thermostat so as to supply the required heat to meet the test's operational temperature.

Under Each set of operational parameters, reactors were fed initially with $10 \mathrm{~L}$ of diluted sludge (animal manure diluted with fresh water) until the appearance of some low biogas production rates for successive operation days and in turn the obtained digested sludge would serve as inoculums for reactors.

Sludge masses were made of dewatered IAF unit skim and kept at $-20 \mathrm{C}$ prior to use as the feed for reactors. Initially, the $\mathrm{pH}$ of digested sludge was adjusted to the range 6- 8 via $2 \mathrm{~N}$ solution of Sodium Hydroxide. This $\mathrm{pH}$ was monitored continuously to make sure it is in that range.

Analysis of COD, TSS and $\mathrm{pH}$ were determined according to the standard methods (APHA, 2010). The biogas production was determined by the displacement of water in a graduated column.

Digest substrates were made of $0.5,1.5,2.5,4.0$ and 5.0:10. IAF skim to the total working volume (each in one reactor; R1, R2, R3, R4 and R5 respectively) at each of the test temperatures ( $25 \mathrm{C}$ and $45 \mathrm{C})$. These combinations were initially mixed via a commercial laboratory blender LBC15.

The five reactors were operated for a period of 30 days under each certain set of operational parameters.

\section{Results and Discussions}

Although disturbances in reactors performance were expected for the early periods of operation, $\mathrm{pH}$ values were mainly within the acceptable rang of 6-8 as shown in Fig.2 for the majority of reactors life times, which indicates well buffering balance of substrate mixtures.

\section{Digestion Performance}

In general, it takes a period of time for the reactor to acclimate and start being effective in the sense of COD removal due to long-chain fatty acids released from the hydrolysis of triglycerides constituents of OG, and the length of this lag period depends upon the IAF skim: working volume ratio; the higher it was, the longer the lag period. From another side, Fig. 3 (a) indicates that higher IAF skim portions had led to lower COD removal efficiency; that is, while the maximum achieved efficiency with reactor R1 was about $72.6 \%$, it did not exceed $43.25 \%$ with reactor $\mathrm{R} 5$, when operated at temperature of $25 \mathrm{C}(68.6 \%, 60.1 \%$ and $52.1 \%$ for $\mathrm{R} 2-\mathrm{R} 4$ respectively). Remarkable enhancements were achieved for the COD removal efficiencies that reached the values of $91.2 \%, 81.5 \%, 72.1 \%, 60.7 \%$ and about $50 \%$ for R1- R5 respectively, by operating the reactors at higher temperature of $45 \mathrm{C}$, as shown by Fig.3 (b). This may be attributed to the thermophilic characteristic of OG content of the IAF skim; e.g., at higher temperatures, OG tends to be more soluble that in turn enhances its biodegradability.

Regarding the TSS constituent, the performance trend of reduction was almost similar to that of COD, which is a reference to the degradable organic composition of the majority of these solids. At operation temperature of $25 \mathrm{C}$, the reduction percentages were $83-49 \%$ for the reactors R1-R5, respectively. The same scenario of high COD removal enhancement at operation temperature of $45 \mathrm{C}$, was repeated with the TSS, where these percentages had the values of $95-77 \%$ for the same mixing ratios.

\section{Biogas Production}

Biogas production in Fig.4 (a) and (b) has shown significant increase via operating the different reactors with the mixed substrates compared to that during the anaerobic digestion of the diluted livestock manure only, as shown in Fig.5. Also, these results had clearly demonstrated, that higher IAF skim (higher COD) has the tendency of higher biogas production at both operation temperatures (25C and $45 \mathrm{C})$. The greater biodegradability and energy potential of carbohydrates that constitute IAF skims might be the main causal for that, in agreement with Thomas et al. (2007).

Highest biogas production rate was measured for R2 (about 4.2 1/day), in comparison with that for R1 (about 3.7 1/day), that hosted the highest IAF skim: working volume ratio at an operation temperature of 25C (Fig.4 (a)). This may be attributed to the higher OG content and salt concentration in the later mixture that inhibits biological transformation at that temperature, and hence, adversely affects the biological activity. That decrease of biogas production rate at higher concentration of IAF skim was overcame by operating the digestion reactors at $45 \mathrm{C}$, (rates of $5.8 \mathrm{l} /$ day and about $5.0 \mathrm{l} /$ day were achieved with $\mathrm{R} 1$ and $\mathrm{R} 2$ respectively), due to the enhanced solubility at high operation temperatures as shown in Fig.4 (b). 


\section{Conclusions}

The anaerobic digestion of wastes that are characterized by high constituency of COD and OG (IAF skim for this study) was tested via co-digestion with livestock manure at different mixing ratios and two operational temperatures in laboratory scaled batch reactors. Good COD removal efficiencies (about 72.6\%- 68.6\%) were achieved while using low portion of these wastes $(5 \%-15 \%$ of the total working volume, respectively) at operation temperature of $25 \mathrm{C}$. This removal efficiency was significantly improved to the values of $91.2 \%-81.5 \%$ for the same mixing ratios, at operation temperature of $45 \mathrm{C}$, which leads to the recommendation of operating such digesters at high temperatures to make benefit of the thermophilic characteristic of such wastes. That later conclusion was so demonstrated by the great enhancement of the biogas production rate of such reactors when operated at high temperatures; while the highest biogas production rate was in the range of 3-4 1/day at temperature $25 \mathrm{C}$, it was raised to the range of $4.5-6 \mathrm{l} /$ day at the temperature $45 \mathrm{C}$.

\section{References}

Al-Maliky Salam B. (2010). Effect of geometrical dimensions and waste water temperature on the performance of an induced air flotation unit for the treatment of industrial waste water. Journal of Modern Applied Science Vol.4 No.6, pp. 14-19.

APHA. (2010), Standard Methods for the Examination of Water and Wastewater, Edited by Lenore S. Clesceri, Arnold E. Greenberg and Andrew D. Eaton. (20th Edition).

Arnold, K.E., Stewart,M. (2008). Surface production operations-design of oil handling systems and facilities. (Vol. 1, $3^{\text {rd }}$ ed.), Gulf Publishing Co, Houston, Texas.

Bouallagui, H., Lahdheb, H., Ben Romdan, E., Rachdi, B., Hamdi, M. (2009). Improvement of fruit and vegetable waste anaerobic digestion performance and stability with co-substrates addition. Journal of Environmental Management 90, 1844-1884.

Fernández J., M. Pérez b, Romero L.I. (2010). Kinetics of mesophilic anaerobic digestion of the organic fraction of municipal solid waste: Influence of initial total solid concentration. Journal of Bioresource Technology, 101, 6322-6328.

Halalsheh, M., Koppes, J., den Elzen, J., Zeeman, G., Fayyad, M., Lettinga, G. (2005). Effect of SRT and temperature on biological conversions and the related scum forming potential. Journal of Water Resources. 39, $2475-2482$.

Hayatdavoudi A. (2006). Removing Oil and Grease from Produced Water Using Micro-Bubble Flotation Technique. Offshore Technology Conference, Texas, USA.

Pan Li and Hideki Tsuge. (2006). Water Treatment by Induced Air Flotation Using Microbubbles. Journal of chemical engineering of Japan, Vol.39, No.8, pp. 896-903.

Thomas, A., Barbara, A., Vitaliy, K., Werner, Z., Karl, M., Leonhard, G. (2007). Biogas production from maize and dairy cattle manure: Influence of biomass composition on the methane yield. Agriculture Ecosystems and Environment 118, 173-182.

Van Ham Niel, Behie Leo A., Svrcek William Y. (2009). Effect of air distribution on the induced air flotation of fine oil in water emulsions. The Canadian Journal of Chemical Engineering, Vol. 61 Issue 4, pp. $541-547$.

Table 1. Characteristics of IAF skim under study

\begin{tabular}{|l|l|}
\hline Characteristic & Amount \\
\hline $\mathrm{pH}$ & $4.5-5$ \\
\hline $\mathrm{COD}(\mathrm{g} / \mathrm{l})$ & 425 \\
\hline $\mathrm{TSS}(\mathrm{g} / \mathrm{l})$ & 120 \\
\hline $\mathrm{OG}(\mathrm{mg} / \mathrm{l})$ & 870 \\
\hline
\end{tabular}




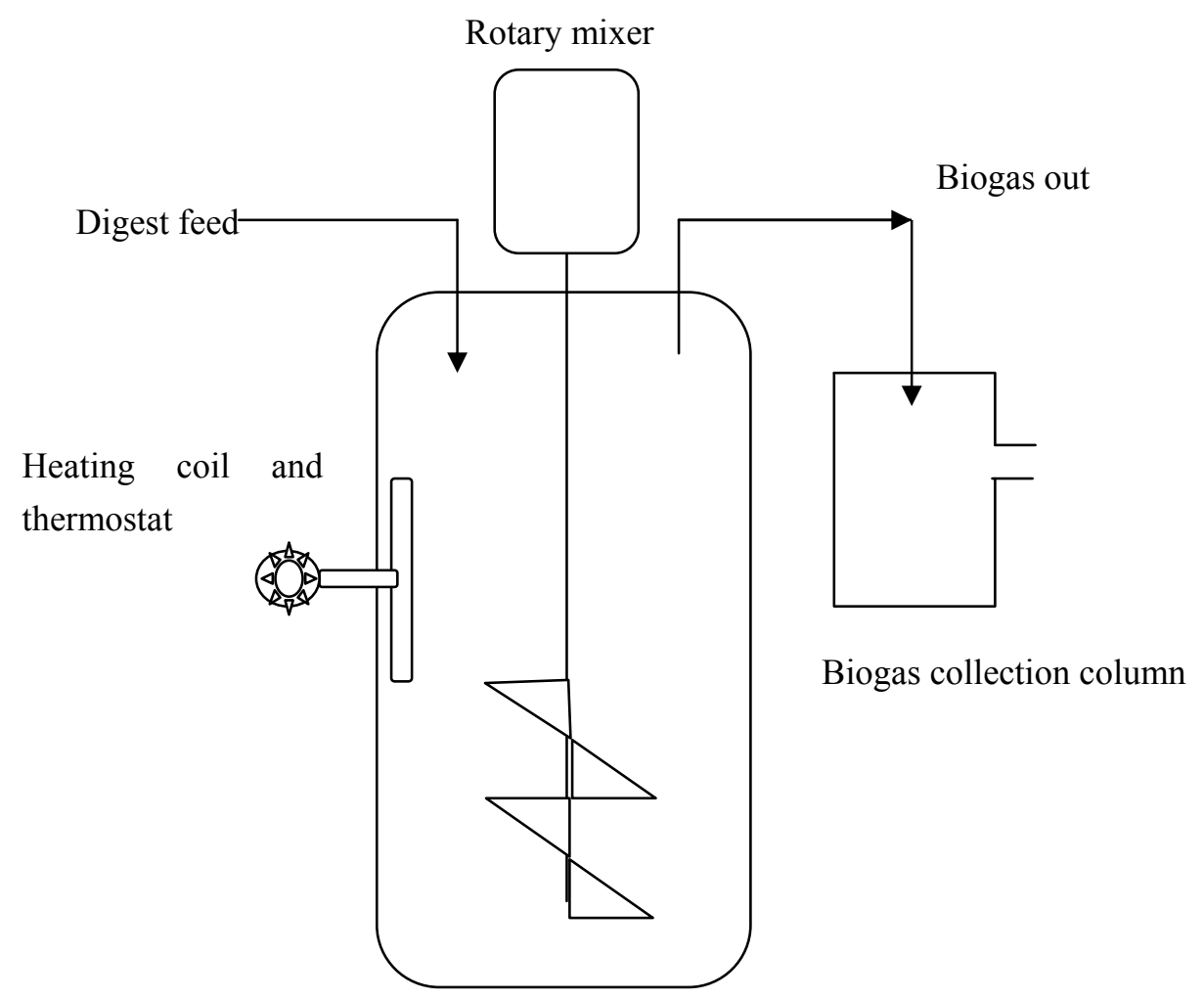

Figure 1. schematic of anaerobic digestion reactor

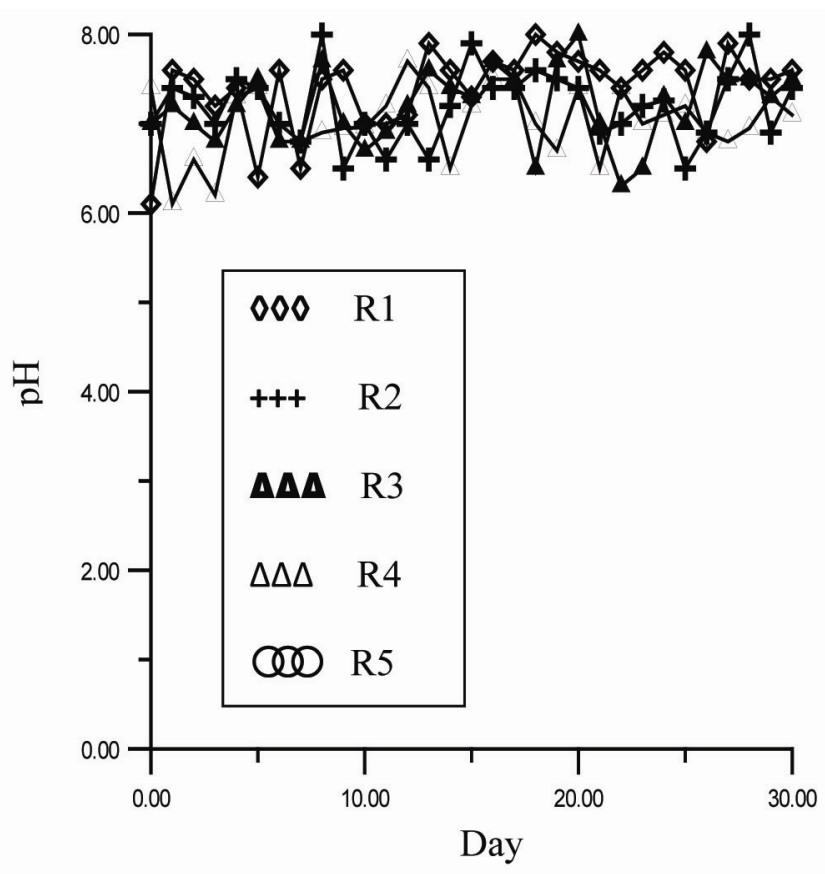

Figure 2. average daily $\mathrm{pH}$ values for test reactors 

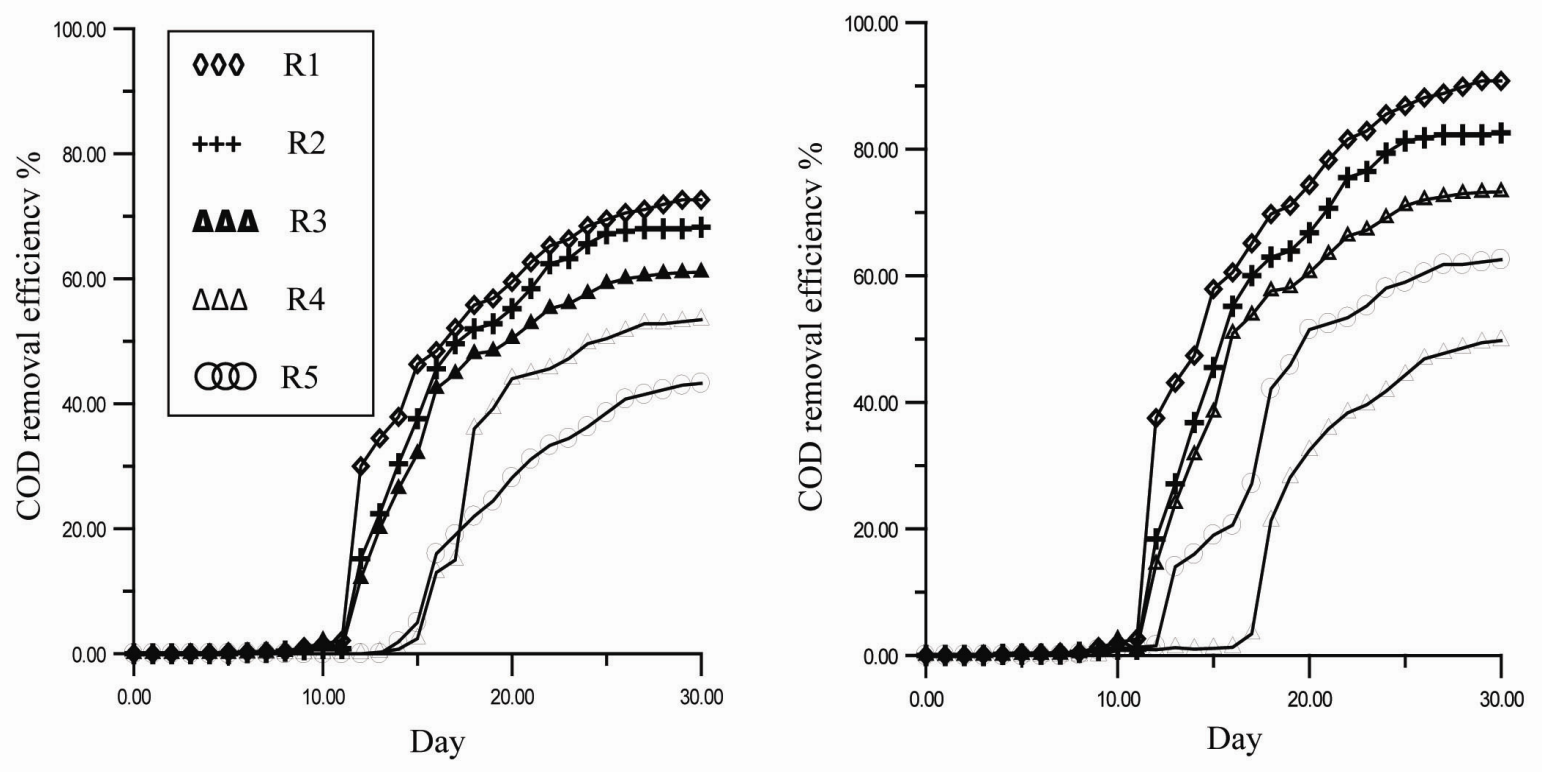

Figure 3. Daily COD removal efficiencies for the reactors R1-R5at;

(a) Temperature of 25C. (b) Temperature of $45 \mathrm{C}$.
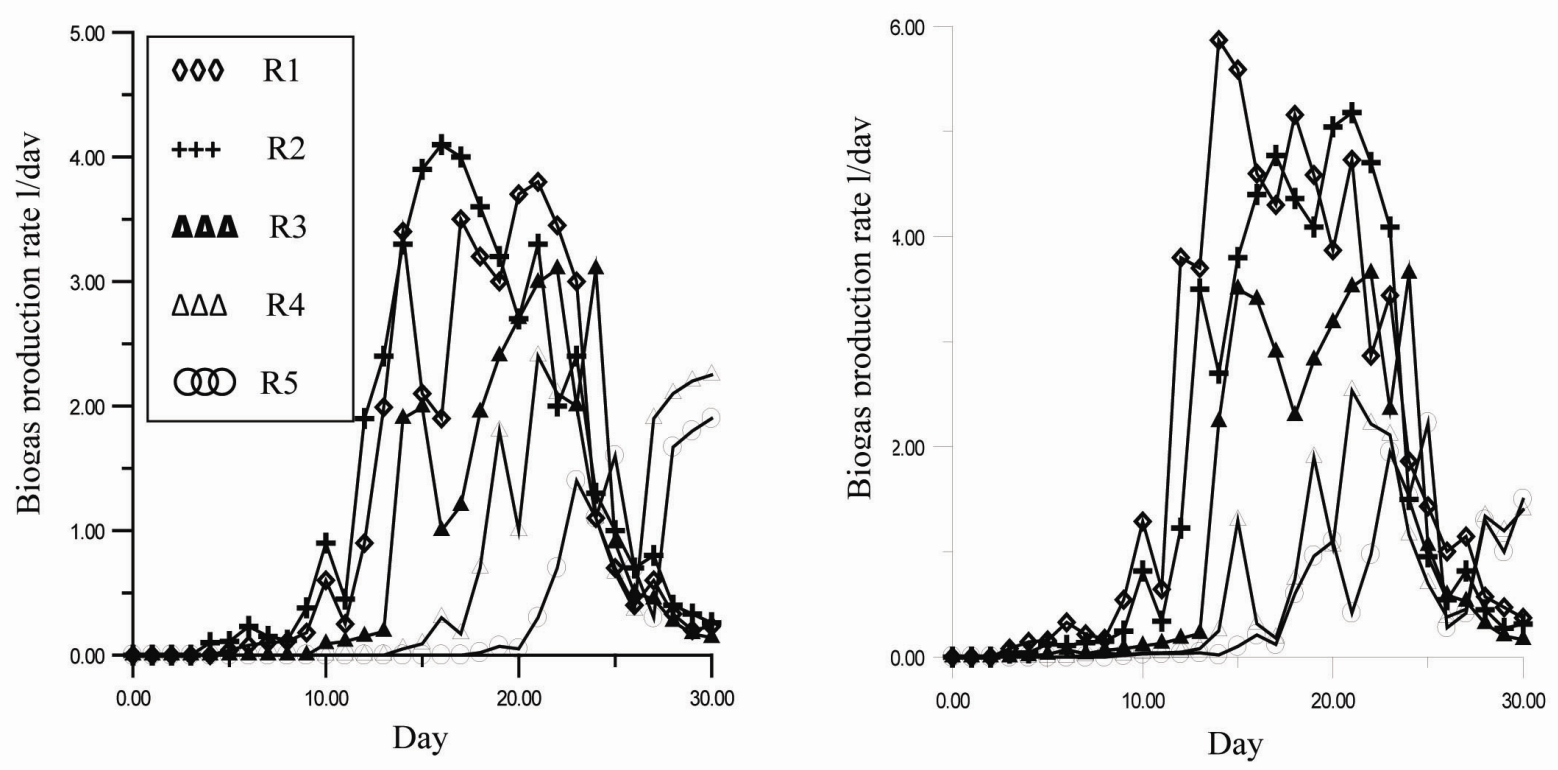

Figure 4. Daily biogas production rate for the reactors R1-R5at;

(a) Temperature of 25C. (b) Temperature of 45C. 


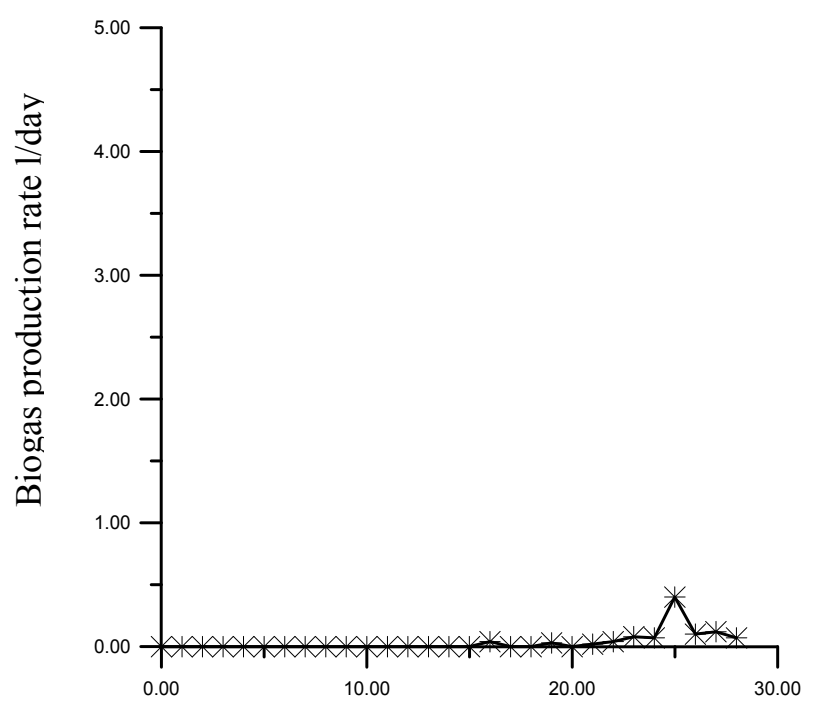

Day

Figure 5. Biogas production rate for anaerobic digestion of livestock manure only. 